\title{
EDITORIAL
}

\section{Candidate interactions}

\author{
F. Kauffmann and R. Nadif
}

I $\mathrm{n}$ the current issue of the European Respiratory Journal, ZHANG et al. [1] present the results of their study on functional polymorphisms of the $\beta_{2}$-adrenoceptor (ADRB2) gene in relation to passive smoking on lung function and exhaled nitric oxide fraction ( $F \mathrm{eNO}$ ) in children 11 yrs of age. They gathered 147 children with contrasted exposure to passive smoking, taking into account exposures recorded at 1 month of age, 6 and 11 yrs. They concluded that smoking had a significant effect on associations between ADRB2 polymorphisms and asthma related phenotypes enhancing the deleterious effect of Arg16 on lung function.

No less than three meta-analyses on the associations of ADRB2 polymorphisms with asthma have been published recently [2-4], with the latter including a new study with data on a large sample studied from childhood to middle age. Overall, there is still no clear pattern and the attributable fraction of $A D R B 2$ polymorphisms to asthma, when considered globally, is likely to be low. However, there is a rather consistent pattern that the Gly16 allele (or Gly16Gln27 haplotype), which is functionally associated with enhanced receptor function, has a protective role towards subphenotypes of asthma in relation to age, specific expression of the disease, such as nocturnal symptoms, and interaction with environmental factors.

The conceptual importance of considering, more systematically, the environment as a key parameter to disentangle the aetiology of complex diseases, such as asthma, was recently underlined [5]. A few genome-wide linkage studies have already searched genetic loci for asthma by considering interaction with smoking, which revealed potential loci not suggested without taking smoking into account [6-8]. Two of these studies suggested loci in the $5 \mathrm{q}$ region, with peaks $\sim 10 \mathrm{~cm}$ apart from the ADRB2 locus [6,7]. The development of genome-wide approaches for associations [9] will highlight new challenges and offer new opportunities. As reminded recently by BALDING [10], "fear of multiple-testing penalties should not deter researchers from making thorough analyses" that concern gene-environment interactions and analyses of subphenotypes, but the problem of chance associations needs to be addressed. Without disputing the combined role of genes and environment in numerous diseases, there is disagreement as to whether searching for interactions between genes or between genes and the environment should be done directly or

Inserm, U780, Epidemiology and Biostatistics, Villejuif, France.

STATEMENT OF INTEREST: None declared.

CORRESPONDENCE: F. Kauffmann, Inserm, U780, 16 ave P.V. Couturier, 94807 Villejuif Cedex, France. Fax: 33 145595169. E-mail: kauffmann@vjf.inserm.fr whether looking at marginal effects first is more efficient [11]. Power issues and publication bias toward significant interactions explain why gene-environment interactions appear much more often in the discussion section of papers than with actual facts. However, evidence in this field is increasing [12] and recent papers in the European Respiratory Journal have tackled gene-environment interactions [13, 14].

Candidate interactions may be defined as the testing of a hypothesis regarding a particular environmental factor in relation to the known function (or potentially the locus) of a specific gene (e.g. endotoxin for CD14), or regarding a particular gene in relation to the known role of a specific environmental factor (such as smoking or coal dust). The former studies are gene-by-environment interactions (the most usual term) whereas the latter are environment-by-gene interactions emphasising that the driving force of the research was the environmental risk factor. Broad approaches are emerging to address the role of families of genes in relation to environment (day care for immune genes) [15]. The key aspect in such research is whether there is an a priori hypothesis or not, and how strong this hypothesis may be physiologically. With increasing knowledge regarding specific pathways various genes along a given pathway, with specific phenotypes along these same pathways $[15,16]$, can be considered through hypotheses testing approaches and will concur with genomewide approaches to unravel the aetiology of complex diseases. Keeping this in mind, more systematic consideration of genetic factors potentially interacting with passive smoking is warranted, as the role of passive smoking is clearly established in modifying lung function over the lifespan and regarding the incidence of, childhood asthma. Large sample size studies, collaborations and meta-analyses based on accessible data will then help to circumvent the limitations related to the lack of power of numerous studies.

The suggestion of the influence of smoking on the association of $A D R B 2$ polymorphisms with asthma previously reported in an adult Chinese population is weak [17]. Whether the interaction was a sufficient "candidate" could be argued, as the role of active smoking as a risk factor of adult asthma is disputed, although smoking clearly modifies the expression of the disease. Although subjects studied were ascertained from a general population of more than 10,000 subjects, the significant interaction was derived from a comparison of 39 asthmatic smokers and 23 nonsmoking controls. Under the title of asthma-related phenotypes, ZHANG et al. [1] studied, in children from the general population, the potential interaction of $A D R B 2$ polymorphisms in the relation of passive smoking with lung function and $\mathrm{FeNO}$, but did not report data regarding asthma, the most studied phenotype in relation to ADRB2 
polymorphisms. Their results are consistent with the hypothesis that the risk of children exposed to tobacco smoke, a risk factor for decreased lung function, an asthma-related phenotype may be enhanced in relation to Arg16. The relevance of examining the interaction of $A D R B 2$ polymorphisms in the association of FeNO with smoking may be argued. The available sample size for the analysis was less than 100 in total. Furthermore, it is well known that smoking decreases FeNO in adults, but the association in children is still unclear and the authors previously reported an increase in FeNO in relation to parental smoking in their population of children [18]. Until a marginal association of smoking with FeNO is established in children, the examination of numerous genes as modifier effects of that association may be premature. Other candidate genes in the understanding of the FeNO phenotype, in particular in relation to smoking, would be of interest, such as nitric oxide synthases or arginases, which share arginine as a common substrate $[19,20]$.

In conclusion, studying the modifying effect of $\beta_{2}$-adrenoceptor gene polymorphisms on the association of passive smoking with childhood lung function belongs to the insufficiently reported area on candidate interactions, but studies on larger sample sizes and replication are needed before such an interaction is considered established.

\section{REFERENCES}

1 Zhang G, Hayden CM, Khoo S-K, et al. $\beta_{2}$-Adrenoceptor polymorphisms and asthma phenotypes: interactions with passive smoking. Eur Respir J 2007; 30: 48-55.

2 Thakkinstian A, McEvoy M, Minelli C, et al. Systematic review and meta-analysis of the association between $\beta 2$ adrenoceptor polymorphisms and asthma: a HuGE review. Am J Epidemiol 2005; 162: 201-211.

3 Contopoulos-Ioannidis DG, Manoli EN, Ioannidis JP. Meta-analysis of the association of beta2-adrenergic receptor polymorphisms with asthma phenotypes. J Allergy Clin Immunol 2005; 115: 963-972.

4 Hall IP, Blakey JD, Balushi KA, et al. $\beta 2$-adrenoreceptor polymorpshims and asthma from childhood to middle age in the British 1958 birth cohort : a genetic association study. Lancet 2006; 368: 771-779.

5 Martinez FD. Genes, environments, development and asthma: a reappraisal. Eur Respir J 2007; 29: 179-178.

6 Colilla S, Nicolae D, Pluzhnikov A, et al. Evidence for geneenvironment interactions in a linkage study of asthma and smoking exposure. J Allergy Clin Immunol 2003; 111: 840-846.
7 Meyers DA, Postma DS, Stine OC, et al. Genome screen for asthma and bronchial hyperresponsiveness: interactions with passive smoke exposure. J Allergy Clin Immunol 2005; 115: 1169-1175.

8 Dizier $\mathrm{MH}$, Bouzigon E, Guilloud-Bataille $\mathrm{M}$, et al. Evidence for gene $x$ smoking exposure interactions in a genome-wide linkage screen of asthma and bronchial hyper-responsiveness in EGEA families. Eur J Hum Genet 2007; [Epub ahead of print PMID:17426724].

9 Moffatt MF, Cookson WOC. After the deluge: post genome genetics of asthma and COPD. Eur Respir J 2007 (in press).

10 Balding DJ. A tutorial on statistical methods for population association studies. Nat Rev Genet. 2006; 7: 781-791.

11 Todd JA. Statistical false positive or true disease pathway? Nat Genet 2006; 38: 731-733.

12 Castro-Giner F, Kauffmann F, de Cid R, Kogevinas M. Gene-environment interactions in asthma. Occup Environ Med 2006; 63: 776-786.

13 Ramadas RA, Sadeghnejad A, Karmaus W, et al. Interleukin-1R antagonist gene and pre-natal smoke exposure are associated with childhood asthma. Eur Respir J 2007; 29: 502-508.

14 Nadif R, Mintz M, Marzec J, Jedlicka A, Kauffmann F, Kleeberger SR. Ill8 and Il18R1 polymorphisms, lung CT and fibrosis: a longitudinal study in coal miners. Eur Respir J 2006; 28: 1100-1105.

15 Hoffjan S, Nicolae D, Ostrovnaya I, et al. Gene-environment interaction effects on the development of immune responses in the 1st year of life. Am J Hum Genet 2005; 76: 696-704.

16 Nadif R, Jedlicka A, Mintz M, Bertrand JP, Kleeberger S, Kauffmann F. Role of TNF and LTA polymorphisms on biological markers of response to oxidative stimuli in coal miners: a model of gene-environment interaction. $J$ Med Gen 2003; 40: 96-103.

17 Wang Z, Chen C, Niu T, et al. Association of asthma with beta(2)-adrenergic receptor gene polymorphism and cigarette smoking. Am J Respir Crit Care Med 2001; 163: 1404-1409.

18 Franklin PJ, Turner S, Mutch R, Stick SM. Parental smoking increases exhaled nitric oxide in young children. Eur Respir J 2006; 28: 730-733.

19 Li H, Romieu I, Sienra-Monge JJ, et al. Genetic polymorphisms in arginase I and II and childhood asthma and atopy. J Allergy Clin Immunol 2006; 117: 119-126.

20 Bergeron C, Boulet LP, Page N, et al. Influence of cigarette smoke on the arginine pathway in asthmatic airways: increased expression of arginase I. J Allergy Clin Immunol 2007; 11: 391-397. 